\title{
Ultra-wide field imaging for ophthalmological evaluation of pregnant women with positive serology for toxoplasmosis
}

\author{
Uso do exame de imagem de campo ultra amplo na avaliação de \\ gestantes com sorologia positiva para toxoplasmose
}

Sérgio Ferreira Santos da Cruz $^{1}$ (D), Isabelle Rocha Gauch ${ }^{1}$ (), Matheus Ferreira Santos da Cruz ${ }^{1}$ (D) Ana Clara Monteiro de Araújo ${ }^{1}$, Natasha Ferreira Santos da Cruz $^{2} \mathbb{0}$, Cléa Nazaré Carneiro Bichara ${ }^{1,3}$ (i)

Medical School, Universidade do Estado do Pará, Belém, PA, Brazil. 2Ophthalmology Department, Universidade Federal de São Paulo, São Paulo, SP, Brazil. ${ }^{3}$ Infectious Diseases Department, Núcleo de Medicina Tropical, Belém, PA, Brazil.

\section{Keywords: \\ Chorioretinitis; Ocular toxoplasmosis; Pregnancy; Diagnostic imaging; Uveitis}

Descritores: Coriorretinite; Toxoplasmose ocular; Gravidez; Diagnostico por imagem; Uveíte

Received on: Feb 21, 2021

Accepted on: Aug 27, 2021

Corresponding author: Sérgio Ferreira Santos da Cruz Travessa Perebebuí, 2.623 - Marco Zip code: 66087-662, Belém, PA, Brazil Phone: 55 (91) 98867-0293

E-mail: sergio.cruz.23@hotmail.com

Institution: Clínica Centro Ocular Tv. Almirante Wandenkolk, 1094, Umarizal, Zip code: 66055-030, Belém, PA, Brazil Phone: (91) 3223-3648 E-mail: centroocularexames@gmail.com

Conflict of interest: no conflict of interest.

Financial support: Fundação Amazônia de Amparo a Estudos e Pesquisa (FAPESPA) provided financial support for this study.

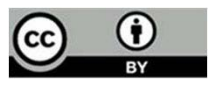

Copyright (C2021

\section{ABSTRACT}

Objective: To screen pregnant women with positive serological results for toxoplasmosis using noninvasive, ultra-wide field retinal imaging.

Methods: Prospective, descriptive longitudinal study including pregnant women with positive serological results for toxoplasmosis seen at three maternal care reference units located in Belém (PA), in the Brazilian Amazon. Patient data were collected via interview. Comprehensive eye examination, including best corrected visual acuity, biomicroscopy, tonometry and ultra-wide field imaging, was performed every three months.

Results: The sample comprised 36 pregnant women. Of these, $52 \%$ had a serological profile consistent with acute toxoplasmosis, whereas $48 \%$ had a serological profile consistent with immunity. Three pregnant women had signs of chorioretinitis on ultra-wide field imaging in the first trimester. An active lesion adjacent to a scarred lesion was detected in one patient. Only women with serological results consistent with acute toxoplasmosis were treated. Treatment with systemic corticosteroids was limited to the patient with active ocular lesion. Follow-up assessment revealed resolution of the ocular lesion and normalization of visual acuity (20/20). All newborns were examined. No signs of congenital toxoplasmosis were found.

Conclusion: Ophthalmological screening of pregnant women with positive serological results for toxoplasmosis should be standardized to prevent vision loss in newborns and mothers. Ultra-wide field retinal imaging can be used as an initial screening strategy to support referral for specialized care, particularly in areas with limited access ophthalmology services.

\section{RESUMO}

Objetivo: Examinar gestantes com sorologia positiva para toxoplasmose de forma não-invasiva, empregando o exame digital da retina de campo ultra amplo.

Métodos: Estudo prospectivo, descritivo e longitudinal envolvendo gestantes com sorologia positiva para toxoplasmose atendidas em três unidades de referência especializadas em cuidados maternos localizadas em Belém (PA), na Amazônia brasileira. Os dados das pacientes foram coletados por meio de entrevista. O exame oftalmológico completo, incluindo acuidade visual com melhor correção, biomicroscopia, tonometria e exame digital da retina de campo ultra amplo, foi realizado a cada três meses.

Resultados: Um total de 36 gestantes foram incluídas nesta análise. O perfil sorológico compatível com toxoplasmose aguda foi detectado em $52 \%$ das gestantes, enquanto as $48 \%$ restantes apresentaram perfil compatível com imunidade. Três gestantes apresentaram sinais de coriorretinite ao exame digital de campo amplo no primeiro trimestre. Apenas uma gestante apresentou lesão ativa adjacente a uma lesão cicatrizada. Somente as gestantes com perfil sorológico compatível com toxoplasmose aguda foram tratadas. $\bigcirc$ uso de corticosteroides sistêmicos se limitou à paciente com lesão ativa. 0 tratamento levou à cicatrização da lesão e à recuperação da acuidade visual da paciente (20/20). Todos os neonatos foram examinados e nenhum apresentou sinais de toxoplasmose congênita.

Conclusão: a implementação do exame oftalmológico de rastreio em gestantes com sorologia positiva para toxoplasmose deve ser padronizada para prevenir a perda da visão em neonatos e mães. $\bigcirc$ exame digital da retina de campo ultra amplo pode ser empregado como estratégia inicial de rastreio, a fim de facilitar o acesso ao cuidado especializado, principalmente em regiões com acesso limitado a serviços oftalmológicos. 


\section{INTRODUCTION}

Toxoplasmosis is a zoonosis caused by the intracellular protozoan Toxoplasma gondii. The disease is widely distributed and affects at least one third of the global population. Prevalence varies widely. However, the disease is more common and clinical presentation appears to be more aggressive in tropical areas. ${ }^{\left({ }^{2}\right)}$ Disease prevalence in Brazil ranges from $60 \%$ to $80 \%,{ }^{(2)}$ Pará being one of the states with the highest prevalence rates. ${ }^{(3)}$

Toxoplasmosis may affect the eye and is a major cause of uveitis in several countries, accounting for up to $60 \%$ of cases of chorioretinitis. ${ }^{(4)}$ In South America, Brazil has the highest prevalence rates of ocular toxoplasmosis, followed by Colombia (up to $17 \%$ and $6 \%$ respectively). ${ }^{(5,6)}$ Toxoplasmic retinochoroiditis can be congenital, although the acquired form of the disease is more common. ${ }^{(7)}$

Pregnancy is thought to trigger ocular toxoplasmosis recurrence. ${ }^{(7,8)}$ During pregnancy, robust immune responses are suppressed to prevent rejection of the fetus by the mother. In pregnant women, reactivation of inflammation induced by infectious diseases is not uncommon and high rates of ocular toxoplasmosis recurrence may be expected. ${ }^{(8)}$

Aside from affecting maternal vision, toxoplasmosis may be vertically transmitted during the reactivation phase of the disease in rare cases. ${ }^{\left({ }^{8}\right)}$ Therefore, ophthalmological examination is particularly important in this group of patients. Reactivation is often suspected in pregnant women with visual symptoms. However, asymptomatic patients may also develop ocular injuries. ${ }^{(9)}$

Traditional fundus retinography includes only the central $30^{\circ}$ or $55^{\circ}$ of the retina. This field of view is ideal for detection of pathological changes in the optic nerve and in the papillary and macular regions, but does not provide appropriate peripheral images. Ancillary imaging modalities, such as ultra-wide field (UWF) retinal imaging, can be used for comprehensive ophthalmological examination and appropriate screening of patients with retinal diseases, with the added benefit of not requiring an ophthalmologist. Ultra-wide field imaging allows faster, non-mydriatic acquisition of high resolution retinal images, which include more than twice the retinal area captured using standard mydriatic retinography. ${ }^{(10)}$

Over $80 \%$ of population infected with T. gondii are thought to be asymptomatic. ${ }^{(11)}$ Like other immunocompetent adults, pregnant women are often asymptomatic or mildly symptomatic, which makes the diagnosis difficult. ${ }^{(2)}$ Ocular toxoplasmosis may also be asymptomatic or mildly symptomatic in healthy individuals. In some cases, the disease may manifest as unrecognized retinochoroidal scars and overall ocular lesions may be found in up to $20 \%$ of infected individuals. ${ }^{(3)}$ Hence the importance of patient follow-up, especially during pregnancy, when reactivation may occur. ${ }^{(4)}$ Examination using non-invasive methods every three months is recommended for patient screening and early disease prevention. Suspected patients should be referred for ophthalmological assessment in order to reduce maternal eye damage and congenital toxoplasmosis.

\section{METHODS}

This was a prospective, descriptive longitudinal study carried out between February 2019 and February 2020, with the approval of the institutional research ethics committee (CAAE: 06102918.2.0000.5174).

Symptomatic or asymptomatic patients with positive serological results for toxoplasmosis (positive immunoglobulin $\mathrm{M}$ and/or $\mathrm{G}$ results) seen at three maternal care referral units located in Belém (PA) were enrolled, regardless of age or gestational age. Exclusion criteria were as follows: refusal to participate, not having been seen at one of the three specialized units selected, positive serological results for other infectious diseases and diagnosis of other eye disease (e.g., uveitis, glaucoma). Serological tests (Enzyme Linked Immuno Sorbent Assay, ELISA) were used for anti-T. gondii IgM and IgG detection. Women with gestational age of 16 weeks or less and positive IgM results were also submitted to IgG avidity testing to distinguish between residual IgM and acute infection.

Participants were interviewed and the following pieces of data collected: age, origin, prenatal care, obstetric data, comorbidities and history of toxoplasmosis, including treatment and eye involvement. Participants were then referred to an ophthalmology service and the following tests performed at 3, 6 and 9 months: best corrected visual acuity (BCVA), biomicroscopy, tonometry and UWF retinal imaging.

Fundus examination using UWF imaging as a screening method in pregnant women sets this study apart. This imaging modality was developed for acquisition of non-mydriatic images using a wide-angle digital camera, ${ }^{(12)}$ with the following purposes: simultaneous evaluation of the peripheral and central retina without the need for eye steering, improved image resolution, short image acquisition and processing time, image manipulation and transmission, acquisition of good quality image in eyes with cataracts or media opacities, easier assessment of pediatric patients and prevention of pupillary dilation. ${ }^{\left({ }^{10}\right)}$ 
Patients with eye lesions on UWF retinal imaging were seen by an ophthalmologist and submitted to indirect ophthalmoscopy and spectral-domain optical coherence tomography (SD-OCT) with Cirrus HD-OCT 5000 (Carl Zeiss Meditec Inc., Dublin, USA).

Newborns (NB) were submitted to clinical and epidemiological assessment shortly after birth and during the next 3 to 6 months. These included serological tests for anti-T. gondii IgM and IgG, transfontanelle ultrasonography and fundus examination.

\section{RESULTS}

Over the course of one year, 122 pregnant women with previous contact with $\mathrm{T}$. gondii were seen at selected maternal care units and referred for ophthalmology consultation. Of these, nine failed to meet inclusion criteria due to positive serological results for HIV/syphilis or glaucoma (eight and one patient respectively) and were excluded. Another 65 failed to attend ophtalmology consultations and twelve were lost follow-up in the subsequent months of pregnancy. The final sample comprised 36 pregnant women.

Patient age ranged from 15 to 38 years (average age, 23.8 years). Twelve out of 36 patients (33.3\%) were pregnant for the first time, 16 (44.4\%) were pregnant for the second time and eight $(22.2 \%)$ had had multiple pregnancies. Most patients (61.1\%) lived in urban centers with only 14 (38.9\%) living in rural areas. Pregnant women in this sample were delivered prenatal care since the first (30 women, $83.3 \%$ ), second (five women, 13.9\%) or third (one woman) trimester of pregnancy (Table 1 ).

Table 1. Epidemiological features of pregnant women with toxoplasmosis seen in ophthalmology consultations from February 2019 to February 2020

\begin{tabular}{lc} 
Epidemiological features & $\mathbf{n}(\%)$ \\
\hline Age, years & \\
$<18$ & $5(13.9)$ \\
$18-35$ & $28(77.8)$ \\
$>35$ & $3(8.3)$ \\
Origin & \\
$\quad$ Urban areas & $22(61.1)$ \\
Rural areas & $14(38.9)$ \\
Parity & \\
$\quad$ First time pregnant & $12(33.3)$ \\
Second time pregnant & $16(44.4)$ \\
Multiple pregnancies & $8(22.2)$ \\
Gestational age, trimester & \\
First & $30(83.3)$ \\
Second & $5(13.9)$ \\
Third & $1(2.8)$ \\
\hline
\end{tabular}

As to systemic symptoms, 50\% of patients were asymptomatic, whereas the remaining 50\% had nonspecific symptoms such as headache, blurred vision and fever/myalgia (55.6\%, 38.7\% and $16.7 \%$ respectively). Eight out of 36 pregnant women $(22.2 \%)$ had a history of toxoplasmosis. Serological tests results revealed a profile consistent with immunity (IgM- and IgG+) in nine patients (25\%). In the remaining 27 patients (75\%), serological profile was consistent with acute toxoplasmosis. Of these, five were positive for IgM and 22 for IgG and IgM. Low and high avidity IgG were detected in $68.2 \%$ and $31.8 \%$ of pregnant women with a serological profile suggestive of acute toxoplasmosis respectively. All tests were performed in $1^{\text {st }}$ trimester of pregnancy (Table 2).

Table 2. Clinical features of pregnant women with toxoplasmosis seen in ophthalmology consultations from February 2019 to February 2020

\begin{tabular}{lc}
\hline Clinical features & $\mathbf{n}(\%)$ \\
\hline Systemic symptoms & $18(50.0)$ \\
Asymptomatic & $10(55 / 6)$ \\
Headache & $7(38.7)$ \\
Blurred vision & $3(16.7)$ \\
Fever/myalgia & \\
Clinical history of toxoplasmosis & $8(22.2)$ \\
Yes & $28(77.8)$ \\
No & \\
Serological profile & $9(25.0)$ \\
\hline IgM- IgG+ & $5(13.9)$ \\
\hline IgM+ IgG- & $22(61.1)$ \\
IgM+ IgG+ & $7(31.8)$ \\
$\quad$ High IgG avidity test & $15(68.2)$ \\
$\quad$ Low lgG avidity test & \\
Ocular lesion & $33(91.7)$ \\
Without lesion & $3(8.3)$ \\
With lesion & 2 \\
$\quad$ Scarred lesion & 1 \\
Active lesion & $18(50.0)$ \\
Treatment regimen & $1(2.8)$ \\
Spiramycin alone & $1(2.8)$ \\
Switched to triple therapy & $16(44.4)$ \\
\hline Switched to triple therapy + systemic corticosteroids & \\
\hline Not treated & \\
\hline immunoglobulin M; IgG: immunoglobulin G. & \\
\hline
\end{tabular}

Current treatment protocols were followed. Patients with a serological profile consistent with acute toxoplasmosis confirmed by avidity testing were treated, regardless of symptoms or presence of eye lesions. In all patients (20), treatment was started with spiramycin. This regimen was maintained throughout pregnancy in 18 cases. In the two remaining cases, spiramycin was replaced by triple therapy with sulfadiazine, pyrimethamine and folinic acid after week 16 of pregnancy. One patient with active eye lesion also received systemic corticosteroids (Table 2).

In this sample, only 2 out of 36 patients (5.56\%) did not show best corrected visual acuity of 20/20 in ophthalmological assessment. The average intraocular pressure 
(IOP) was $14.7 \mathrm{mmHg}$ in the right eye (RE) and $15.2 \mathrm{mmHg}$ in the left eye (LE) (standard deviation, 4.35 and 2.94, respectively). Three (8.3\%) pregnant women had lesions consistent with chorioretinitis on UWF imaging at the 3-month follow-up. Of these, one (2.7\%) had an active lesion next to a chorioretinal scar, whereas the remaining two had scarred lesions and were asymptomatic. Both asymptomatic patients were positive for IgG and IgM and had high IgG avidity. Ophtalmologic assessment revealed BCVA of 20/30 in the LE in one patient (Figure 1A) and BCVA of 20/20 in the RE in the other one (Figure 1B).

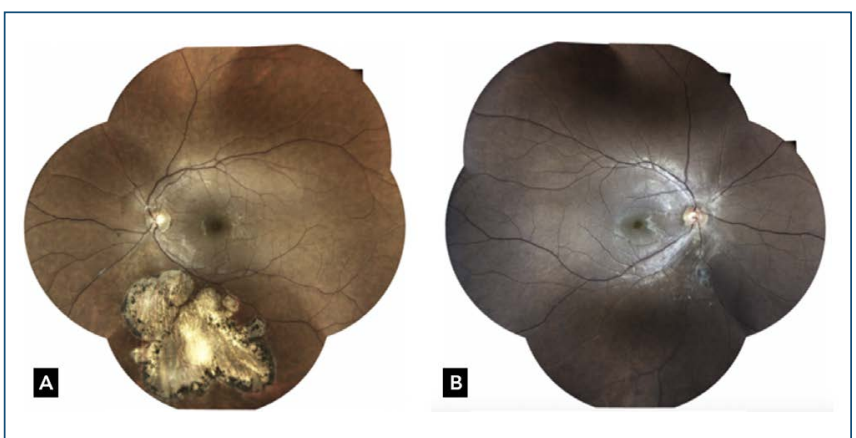

Figure 1. (A) Scarred lesion in lower temporal arcade of left eye. (B) Scarred lesions in lower nasal arcade of right eye.

The patient with active eye lesion was 12 weeks pregnant and reported blurred vision in the LE for 1 week. She had no ocular or family history, had tested positive for Toxoplasma IgG and IgM and had high avidity test results. Ophtalmologic examination revealed BCVA of 20/30 in the LE and no abnormalities in the RE. Biomicroscopy of the affected eye (LE) revealed conjunctival hyperemia $(1+)$, absence of corneal keratic precipitates, anterior chamber reaction (4+) (Figure 2) and increased IOP (27 mmHg). Fundoscopy showed a slightly nasally elevated optic disc, a cup-to-disk ratio of o.1, macula with reduced brightness and active temporal chorioretinitis, which spared the macula and was associated with satellite lesions and perilesional vasculitis, two temporal dot-and-blot hemorrhages and one dotand-blot hemorrhage above to the optic disc (Figure 3A). Optical coherence tomography (OCT) revealed vitreous cells, presence of an inflammatory membrane in the fovea and hyperreflective foci in the inner retinal layers, temporal to the fovea (Figure $3 \mathrm{C}$ ).

This patient was treated between weeks 12 and 22 of pregnancy. Spiramycin was given first. Oral corticosteroids were then introduced due to the size of the active lesion. Topical treatment for anterior uveitis and high IOP

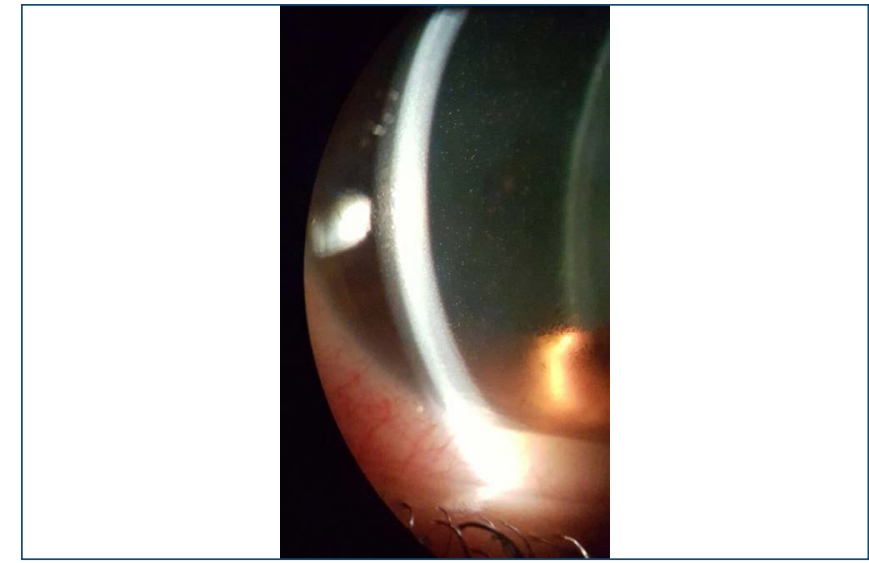

Figure 2. Conjunctival hyperemia (1+) and anterior chamber reaction $(4+)$.

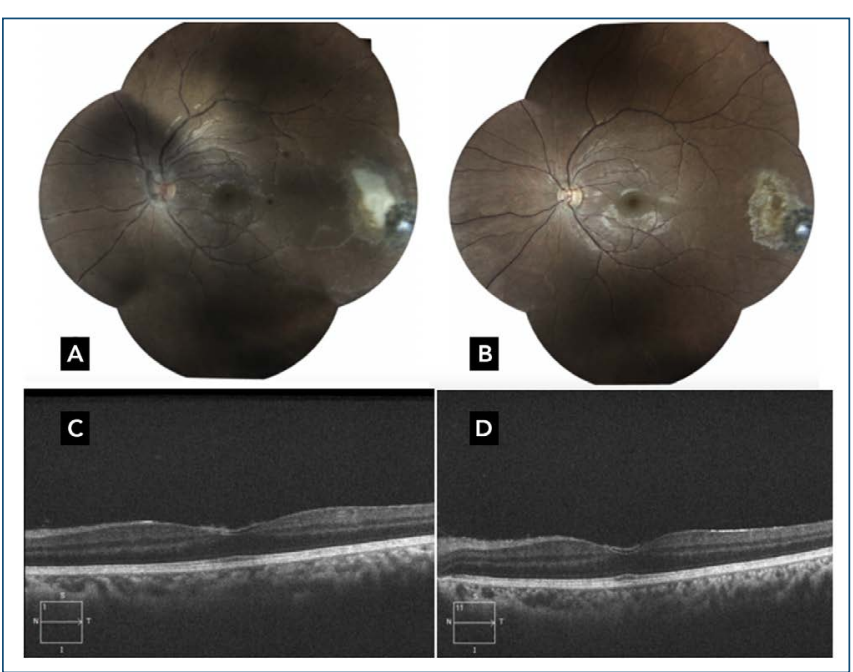

Figure 3. Ultra-Wide Field images before (A) and after (B) treatment. Optical coherence tomography images before (C) and after (D) treatment.

consisted of $0.1 \%$ dexamethasone and $0.5 \%$ timolol maleate eye drops. After week 16, the patient was switched to triple therapy. At the 3-month follow-up, LE vision had improved (AV 20/20) and IOP in that eye was $17 \mathrm{mmHg}$. The conjunctiva and the cornea were clear and no signs of anterior chamber reaction or synechiae were found. The active lesion had healed, vasculitis had improved and bleeding had resolved (Figure 3B). No vitreous cells were seen in OCT and the inflammatory membrane had improved (Figure 3D).

Pregnant women in this sample did not develop new ocular lesions during pregnancy. Newborns were examined and no signs of congenital toxoplasmosis detected. However, the patient with active eye lesion developed pre-eclampsia and progressed to premature delivery at 29 weeks. The baby died of neonatal sepsis within 6 weeks of birth. 


\section{DISCUSSION}

This was the first prospective study carried out in the Brazilian Amazon to screen for ocular toxoplasmosis in pregnant women. This is an important measure at this location, given the high regional prevalence of the disease. ${ }^{(5)}$

Retinochoroidal scars associated with toxoplasmosis were detected in $8.3 \%$ of pregnant women in this sample. In one case $(2.7 \%)$ an active lesion overlying an old lesion was found. Bosch-Driesden et al. ${ }^{(13)}$ reported that $9 \%$ of women with ocular toxoplasmosis experience recurrence during pregnancy. The lower percentage of pregnant women with recurrent lesions in this study may have reflected prospective design and active diagnostic investigation.

In pregnant women, newly diagnosed ocular toxoplasmosis is far less common than recurrent toxoplasmic retinochoroiditis. ${ }^{(14)}$ Reactivation of the inflammatory process associated with the infectious disease is not uncommon and higher rates of ocular toxoplasmosis recurrence may be expected. ${ }^{(8,15)}$ While pregnancy is thought to provide favorable conditions for development of more aggressive forms of the disease, ${ }^{(16)}$ it has also been argued that it does not impact toxoplasmosis recurrence or clinical features. ${ }^{(17,18)}$

As any other patient, pregnant women acquire toxoplasma infection through consumption of undercooked or raw meat containing cysts, or vegetables or water infected with oocysts. Infection via drinking water has also been reported in Brazil. ${ }^{(19)}$ The fact that a minority of participants (38.9\%) in this study lived in rural areas may have reflected difficulties associated with traveling to referral centers. This is a crucial piece of information, since evidence suggests that pregnant women living in rural areas have a higher and earlier risk of infection than those living in urban areas. ${ }^{(20)}$

Serological tests designed to detect specific antibodies, such as anti-T. gondii IgG and IgM, should be routinely performed in pregnant women In Brazil. ${ }^{(21)}$ Confirmation of toxoplasmosis diagnosis is vital to prevent potential vertical transmission of $\mathrm{T}$. gondii and guide appropriate treatment, in order to minimize fetal sequelae. ${ }^{(22)}$ With regard to ocular lesions, detection of retinochoroidal scars and in patients with anti-toxoplasma IgG antibodies is arguably sufficient to confirm the diagnosis of toxoplasma infection. ${ }^{(21)}$

Retinochoroidal lesions located in the far peripheral retina may be missed even by the most experienced specialists. Therefore, UWF imaging can be used as an ancillary tool for detection and documentation of such lesions in cases of uveitis, ${ }^{(23)}$ including those associated with ocular toxoplasmosis. This technology has only been commercially available in recent years. Hence the scarcity of reports addressing the advantages of UWF imaging for diagnosis of other retinal diseases. ${ }^{(16,23)}$ Overall, UWF imaging provides similar image resolution to conventional retinography, with the added benefits of higher sensitivity for detection of pathological changes in the peripheral retina and ability to acquire images through small pupils. Disadvantages of UWF imaging include higher cost in the short term, limited access to the technology in some geographic areas and need of trained and qualified professionals. However, benefits may outweigh the costs in the long term. According to some researchers, UWF imaging should be the ocular imaging modality of choice for detection, documentation and monitoring of ocular toxoplasmosis, if available. ${ }^{(16)}$

Optical coherence tomography is a non-invasive imaging modality well suited for investigation of retinal morphology and pathological changes. In cases of ocular toxoplasmosis, OCT may help distinguish between old retinochoroidal scars and active lesions, since small serous retinal detachments, neovascular or epiretinal membrane formation and other abnormalities can be detected. ${ }^{(24)}$ In this study, the only active lesion described could not be seen in OCT B-scans. Nevertheless, OCT enabled the detection of an inflammatory membrane in the fovea. In that patient, a severe inflammatory reaction associated with hypertensive uveitis and vasculitis was detected. However, the macula and the optic disc were spared and good BCVA was retained. Visual symptoms are typically secondary to vitritis or, less frequently, to macular or optic nerve involvement. ${ }^{(25)}$ Macular scar formation or optic atrophy may lead to permanent vision loss and up to $24 \%$ of affected patients may have 20/200 vision or less in at least one eye. ${ }^{(18)}$

In cases of intrauterine infection, the baby may be born without complications. However, aggravations tend to occur later in life. Awareness of active toxoplasmosis during pregnancy is particularly important, since infected NBs may develop cerebral calcifications, chorioretinitis, blindness, delayed neuropsychomotor development, microcephaly, hydrocephalus, bulging fontanels, meningoencephalitis, strabismus, hepatosplenomegaly, skin rash, petechiae, jaundice and pneumonia. ${ }^{(8)}$

In a sample comprising more than 2,000 infected pregnant women who were prospectively followed and treated, $79 \%$ of NBs were unaffected by congenital toxoplasmosis and birth defects occurred in less than $1 \%$ of the cases. 
These findings are in keeping with results of this study, in which none of the NBs had manifestations of congenital toxoplasmosis, and emphasize the significance of timely follow-up and diagnosis. The risk of vertical transmission ranges from $10 \%$ to $15 \%$ when infection occurs during the first trimester of pregnancy. However, the likelihood increases sharply and can be as high as $70 \%$ to $80 \%$ when infection occurs during the third trimester. ${ }^{(26)}$

In this study, pregnant women with acute toxoplasmosis were treated, regardless of symptoms. A single patient received ocular treatment due to an active lesion. This approach was adopted to mitigate vision damage and the risk of fetal transmission.

Treatment of pregnant patients with ocular toxoplasmosis is controversial. ${ }^{(27,28)}$ In a survey with 457 ophthalmologists, $25 \%$ of specialists and $40 \%$ of general ophthalmologists "were not sure" about how to manage a pregnant patient with recurrent ocular toxoplasmosis. (11) Factors such as risk of maternal vision loss, protection of the fetus against transplacental transmission and fetal adverse events should be taken into account in therapeutic decision making. ${ }^{(11)}$

In Brazil, the Ministry of Health recommends systemic treatment of patients with laboratory confirmation of toxoplasmosis. The treatment regimen proposed includes spiramycin administration until week 16 of pregnancy, then introduction of a triple scheme consisting of sulfadiazine, folinic acid, according to some parameters. ${ }^{(20,29)}$ Triple therapy is thought to be the regimen of choice in cases of ocular toxoplasmosis. ${ }^{(26)}$ Positive ocular response to treatment is defined as a sharpening of retinochoroidal lesion borders and decrease in the number of vitreous cells. ${ }^{(30)}$

Oral corticosteroids can be given as an adjuvant medication within 48 hours of initiation of antimicrobial therapy. These drugs are often indicated to reduce tissue damage induced by inflammatory responses in cases with lesions close to the fovea or optic disk, large active lesions or severe vitreous inflammation. Topical corticosteroids may also be indicated in cases of ocular pain, redness, photophobia or moderate to severe inflammation of the anterior chamber. ${ }^{(27)}$ In patients with more than one of these signs, topical corticosteroids can be added to the treatment. Oral corticosteroids may also be used depending on the size of the lesion.

Convenience sampling is one of the limitations of this study, since pregnant women who were invited to participate had sought assistance at public health units due to toxoplasmosis and were referred to an ophthalmology clinic. Poor access to public health services is common in Brazil, especially in rural or smaller urban areas.
Deployment of telemedicine services equipped with UWF imaging may allow appropriate screening of patients with limited access to ophthalmology services and facilitate adherence to the current proposal. Color fundus images should be analyzed by a retina specialist. Patients with ocular lesions should referred to health units for indirect ophthalmoscopic assessment and other tests.

\section{CONCLUSION}

Health care provision to women, especially during pregnancy, is of utmost importance in public health policies. Antenatal care allows timely implementation of prophylactic measures against maternal-fetal transmission of several diseases, including highly prevalent diseases such as toxoplasmosis.

Pregnant women at risk of toxoplasmosis may be submitted to ophtalmic examination or screened via telemedicine using ultra-wide field imaging. Ophthalmological screening every three months is a potentially effective diagnostic measure in these cases and may prevent disease progression. Screening strategies may facilitate provision of assistance to pregnant women with limited access to ophtalmic care. Ultra-wide field imaging is a promising initial screening tool, with high sensitivity for identification of ocular lesions and the added benefit of not requiring an ophthalmology specialist. Pregnant patients with imaging findings suggestive of infection should be referred to a specialized service.

The screening strategy described has already been implemented for other ocular diseases and may be indicated to prevent retinopathy of prematurity.

Ultra-wide field imaging allowed the detection of retinochoroidal lesions in $8.3 \%$ of pregnant women in this study. This is a considerable rate, which is expected to increase with wider use of this diagnostic imaging modality. Given the condition may be asymptomatic, specialists and obstetricians must be informed of the importance of ophthalmic screening in pregnant women at risk of toxoplasmosis development. Ophtalmologists should be aware of appropriate therapeutic regimens and novel, non-invasive diagnostic technologies.

\section{REFERENCES}

1. Avelar JB, Da Silva MG, Rezende HH, Storchilo HR, Do Amaral WN, Xavier IR, et al. Epidemiological factors associated with Toxoplasma gondii infection in postpartum women treated in the public healthcare system of goiânia, state of Goiás, Brazil. Rev Soc Bras Med Trop. 2018;51(1):57-62.

2. Santos AL, TercasTrettel AC, Ribeiro L, Vasconcellos ML, Zenazokenae LE, Santos MA, et al. Serological study on toxoplasmosis in the Haliti-Paresi community of the Utiariti indigenous territory, Campo Novo do Parecis, Mato Grosso, Brazil. Parasite Epidemiol Control. 2019;5:e00097. 
3. Bichara CN, Cantos GA, Tostes CL, Freitas JJ, Carmo EL, Póvoa M, et al. Incidence of congenital toxoplasmosis in the city of Belém, state of Pará, northern Brazil, determined by a neonatal screening program. Rev Soc Bras Med Trop. 2012;45(1):122-4.

4. Majumder PD, Ghosh A, Biswas J. Infectious uveitis: an enigma. Middle East Afr J Ophthalmol. 2017;24(1):2-10.

5. Grigg ME, Dubey JP, Nussenblatt RB. Ocular toxoplasmosis: lessons from Brazil. Am J Ophthalmol. 2015;159(6):999-1001.

6. De-La-Torre A, Gonzalez G, Diaz-Ramirez J, Gomez-Marin JE. Screening by ophthalmoscopy for Toxoplasma retinochoroiditis in Colombia. Am J Ophthalmol. 2007;143(2):354-6.

7. Cortés JA, Roncancio A, Uribe LG, Cortés-Luna CF, Montoya JG. Approach to ocular toxoplasmosis including pregnant women. Curr Opin Infect Dis. 2019;32(5):426-34.

8. Braakenburg AM, Crespi CM, Holland GN, Wu S, Yu F, Rothova A. Recurrence Rates of Ocular Toxoplasmosis During Pregnancy. Am J Ophthalmol. 2014;157(4):767-73.

9. Olival V, Correia A, Bello A, Cabugueira A, Nunes MJ. Ocular toxoplasmosis reactivation during pregnancy. Acta Obstet Ginecol Port. 2014;8(1):82-3.

10. Kothari N, Pineles S, Sarraf D, Velez F, Heilweil G, Holland G, et al. Clinicbased ultra-wide field retinal imaging in a pediatric population. Int J Retina Vitreous. 2019;5(Suppl 1):21.

11. Brydak-Godowska J, Moneta-Wielgoś J, KęcikD, Borkowski PK. Management of toxoplasmic retinochoroiditis during pregnancy, postpartum period and lactation: clinical observations. Med Sci Monit. 2015;21:598-603.

12. Sarao V, Veritti D, Borrelli E, Sadda SV, Poletti E, Lanzetta P. A comparison between a white LED confocal imaging system and a conventional flash fundus camera using chromaticity analysis. BMC Ophthalmol. 2019;19(1):231.

13. Bosch-Driessen LE, Berendschot TT, Ongkosuwito JV, Rothova A. Ocular toxoplasmosis: clinical features and prognosis of 154 patients. Ophthalmology. 2002;109(5):869-78.

14. Ongkosuwito JV, Bosch-Driessen EH, Kijlstra A, Rothova A. Serologic evaluation of patients with primary and recurrent ocular toxoplasmosis for evidence of recent infection. Am J Ophthalmol. 1999;128(4):407-12.

15. Kump LI, Androudi SN, Foster CS. Ocular toxoplasmosis in pregnancy. Clin Experiment Ophthalmol. 2005;33(5):455-60.

16. Cho M, Kiss S. Detection and monitoring of sickle cell retinopathy using ultra wide-field color photography and fluorescein angiography. Retina. 2011;31(4):738-47.

17. Braakenburg AM, Rothova A. Clinical features of ocular toxoplasmosis during pregnancy. Retina. 2009;29(5):627-30.
18. Reich M, Ruppenstein M, Becker MD, Mackensen F. Risk of recurrence of preexisting ocular toxoplasmosis during pregnancy. Ocul Immunol Inflamm. 2015;23(3):240-5.

19. Torgerson PR, Mastroiacovo P. The global burden of congenital toxoplasmosis: a systematic review. Bull World Health Organ. 2013;91(7):501-8.

20. Silva MG, Câmara JT, Vinaud MC, Castro AM. Epidemiological factors associated with seropositivity for toxoplasmosis in pregnant women from Gurupi, State of Tocantins, Brazil. Rev Soc Bras Med Trop. 2014;47(4):46975.

21. Peyron F, Wallon M, Kieffer F, Garweg J. Toxoplasmosis. In: Wilson CB, Nizet V, Maldonado YA, Remington JS, Klein JO. Remington and Klein's infecious diseases of the fetus and newborn infant. 8th ed. Philadelphia: Saunders; 2016. p. 949-1042.

22. Oz HS. Maternal and congenital toxoplasmosis, currently available and novel therapies in horizon. Front Microbiol. 2014;5:385.

23. Kaines A, Tsui I, Sarraf D, Schwartz S. The use of ultra wide field fluorescein angiography in evaluation and management of uveitis. Seminars in Ophthalmology. 2009;24(1):19-24.

24. Oréfice JL, Costa RA, Scott IU, Calucci D, Oréfice F, Grupo Mineiro de Pesquisa em Doenças Oculares Inflamatórias (MINAS). Spectral optical coherence tomography findings in patients with ocular toxoplasmosis and active satellite lesions (MINAS Report 1). Acta ophthalmologica. 2013;91(1):41-7.

25. Ozgonul C, Besirli CG. Recent developments in the diagnosis and treatment of ocular toxoplasmosis. Ophthalmic Res. 2017;57(1);1-12.

26. Wallon M, Peyron F. Effect of antenatal treatment on the severity of congenital toxoplasmosis. Clin Infec Dis. 2016;62(6):811-2.

27. Holland GN, Lewis KG. An update on current practices in the management of ocular toxoplasmosis. Am J Ophthalmol. 2002;134:102-14.

28. Lum F, Jones JL, Holland GN, Liesegang TJ. Survey of ophthalmologists about ocular toxoplasmosis. Am J Ophthalmol. 2005;140(4):724-6.

29. Brasil. Ministério da Educação. Portaria n 356, de 20 de março de 2020. Atuação dos alunos dos cursos da área de saúde no combate à pandemia do COVID-19 (coronavírus). Brasília, DF: Diário Oficial da União; 2020 [citado 2021 Ago 23]. Disponível em: http://pesquisa.in.gov.br/imprensa/ jsp/visualiza/index.jsp?data $=12 / 03 / 2020$ \&jornal $=515 \&$ \&agina $=185$

30. Silveira C, Muccioli C, Nussenblatt R, Belfort Jr R. The Effect of long-term intermittent trimethoprim/sulfamethoxazole treatment on recurrences of toxoplasmic retinochoroiditis: 10 years of follow-up. Ocul Immunol Inflamm. 2015;23(3):246-7. 